\title{
SHORT COMMUNICATION The Effect of Sequential Heat Treatment on Resistance and Temperature Coefficient of Resistance (TCR) of $\mathrm{NiCr}$ Thin Films
}

\author{
B. STEPIEN and K. WOJTCZAK \\ Industrial Institute of Telecommunication, Warsaw, Poland
}

(Received June 17, 1981; in final form October 8, 1981)

\begin{abstract}
Measurements have been made of resistivity as a function of temperature in the range 290 to $600^{\circ} \mathrm{K}$ for vacuum deposited $\mathrm{NiCr}$ thin films subjected to different heat treatments in air.

While the films prior to heat treatment exhibit a negative TCR in the range 290 to $390^{\circ} \mathrm{K}$, after heat treatment the TCR becomes positive and almost constant, in the temperature range 290 to $600^{\circ} \mathrm{K}$. The TCR increases when further sequential cycles of heat treatment are applied.
\end{abstract}

\section{INTRODUCTION}

Vacuum deposited thin films of $\mathrm{NiCr}$ are used as resistive material in especially high quality microelectronic circuitry when high stability and low I'CR are required. As reported in various papers the TCR of $\mathrm{NiCr}$ films can exhibit both negative or positive values. The negative values have been usually explained by the presence of semiconducting chromium oxide (e.g. Herbert and Lassak ${ }^{1,2}$ ).

In this paper the effect of heat treatment on $\mathrm{NiCr}$ thin films with initially negative TCR values has been presented.

\section{EXPERIMENTAL}

$80: 20 \mathrm{NiCr}$ was evaporated from a zirconium oxide crucible heated by electron beam bombardment and deposited on to Corning Glass 7059 substrate. During deposition, the rate of deposition, the amount of $\mathrm{NiCr}$ deposited on a reference shutter, the amount of $\mathrm{NiCr}$ deposited on the substrate, and the resistance of the films was measured.

The vacuum was obtained by the usual combination of rotary and diffusion pumps. The conditions of the vacuum deposition were as follows:

pressure immediately before evaporation,

$9 \times 10^{-6}$ torr.

pressure at the end of the evaporation, $6 \times 10^{-6}$ torr. amount of $\mathrm{NiCr}$ deposited on shutter and on substrate were equal.

temperature of substrates during deposition, $430^{\circ} \mathrm{K}$. thickness of film, approximately $20 \mathrm{~nm}$. time of evaporation, 60 seconds.
Immediately after the $\mathrm{NiCr}$ deposition a conducting layer was evaporated. Test resistors were then prepared by two-step photolithography.

The parameters of the sequential heat treatments are specified in Table I for the test resistor number $19 \mathrm{~b} 4$ and in Table II for test resistor number $19 \mathrm{~b} 5$. Before each heat treatment and after the last one the resistance in the range from 293 to approximately $525^{\circ} \mathrm{K}$ was measured.

\section{RESULTS}

Results of the measurements of resistance before each heat treatment cycle and after the last one, as well as measurements of TCR, are given in Tables I and II. The resistance-temperature relationships for the two test resistors, $19 \mathrm{~b} 4$ and $19 \mathrm{~b} 5$, are shown in Figures 1 and 2 respectively. All the curves shown are for increasing temperature. Curves for reducing temperature were not generally measured as the samples were heat treated at the end of the temperature increase. However, where curves for increasing temperature were measured they corresponded within the limits of experimental error to the subsequent curves obtained at rising temperature.

\section{DISCUSSION}

The resistance-temperature relationship before the first heat treatment consists of two different regions. At temperatures below $400^{\circ} \mathrm{K}$ the TCR is negative. Above $430^{\circ} \mathrm{K}$ the resistance increases irreversibly. 
TABLE I

Parameters of heat treatments for test resistor $19 \mathrm{~b} 4$. (c.f. Figure 1)

\begin{tabular}{|c|c|c|c|c|}
\hline \multirow{2}{*}{$\begin{array}{l}\text { Heating curve } \\
\text { prior to heat } \\
\text { treatment }\end{array}$} & \multicolumn{2}{|c|}{ Initial Values } & \multirow{2}{*}{$\begin{array}{l}\text { Parameters of heat } \\
\text { treatments } \\
\text { Max. Temperature }\end{array}$} & \multirow{2}{*}{ Time } \\
\hline & $\mathrm{R}_{0}$ & TCR & & \\
\hline & $(\Omega / \square)$ & $\left(\mathrm{ppm} /{ }^{\circ} \mathrm{K}\right)$ & $\left({ }^{\circ} \mathrm{K}\right)$ & (h) \\
\hline I & 132 & -40 & 600 & 43 \\
\hline II & 190 & +6 & 620 & 130 \\
\hline \multirow[t]{2}{*}{ III } & 210 & +100 & 635 & 7 \\
\hline & & & 655 & \\
\hline IV & 213 & +130 & 675 & 3.5 \\
\hline \multirow[t]{2}{*}{ V } & 236 & +170 & 625 & 78 \\
\hline & & & $595^{\mathrm{a}}$ & $100^{\mathrm{a}}$ \\
\hline $\mathrm{VI}^{\mathrm{b}}$ & $261^{b}$ & $+200^{b}$ & - & - \\
\hline
\end{tabular}

${ }^{\mathrm{a}}$ Two heat treatments in sequence after heating curve $\mathrm{V}$. bNo heat treatment after heating curve VI.
TABLE II

Parameters of heat treatment for resistor number $19 \mathrm{~b} 5$ (c.f. Figure 2)

\begin{tabular}{|c|c|c|c|c|}
\hline \multirow{2}{*}{$\begin{array}{l}\text { Heating curve } \\
\text { prior to } \\
\text { heat treatment }\end{array}$} & \multicolumn{2}{|c|}{ Initial values } & \multirow{2}{*}{$\begin{array}{l}\text { Parameters of heat } \\
\text { treatments } \\
\text { Max. Temperature }\end{array}$} & \multirow[b]{2}{*}{ Time } \\
\hline & $R_{0}$ & TCR & & \\
\hline & \multicolumn{3}{|c|}{$(\Omega / D)\left(\mathrm{ppm} /{ }^{\circ} \mathrm{K}\right)\left({ }^{\circ} \mathrm{K}\right)$} & (h) \\
\hline I & 132 & -35 & 600 & 25 \\
\hline II & 180 & +10 & 625 & 45 \\
\hline III & 204 & +35 & 600 & 60 \\
\hline $\mathrm{IV}^{\mathrm{a}}$ & $205^{\mathrm{a}}$ & $+40^{\mathrm{a}}$ & - & - \\
\hline
\end{tabular}

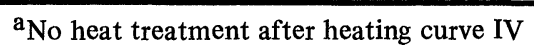

After the first heat treatment the resistance is found to increase linearly over the full range of temperature. This type of resistance-temperature relationship can therefore be described by one TCR value. After the

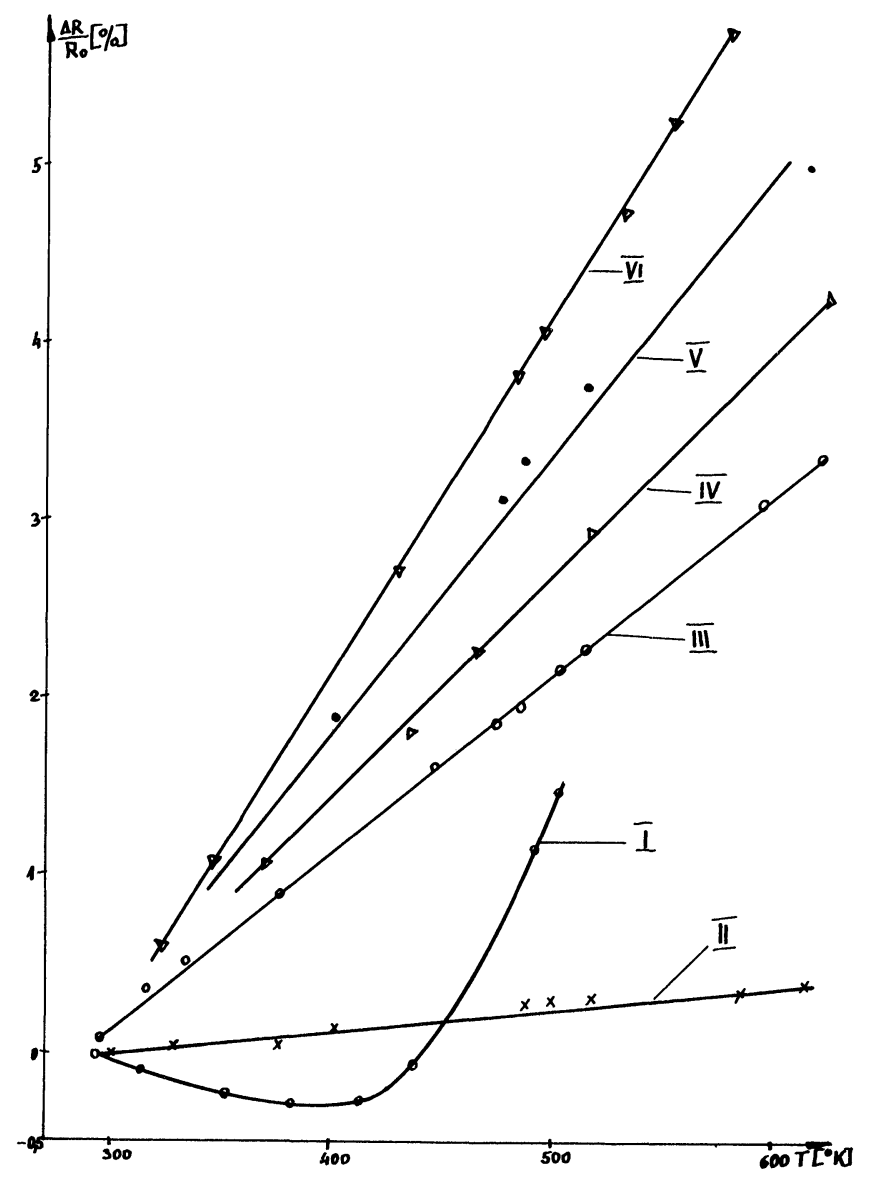

FIGURE 1 Temperature characteristics of resistance for resistor $19 \mathrm{~b} 4$ before each heat treatment (curves I-V) and after the last one (curve VI). 


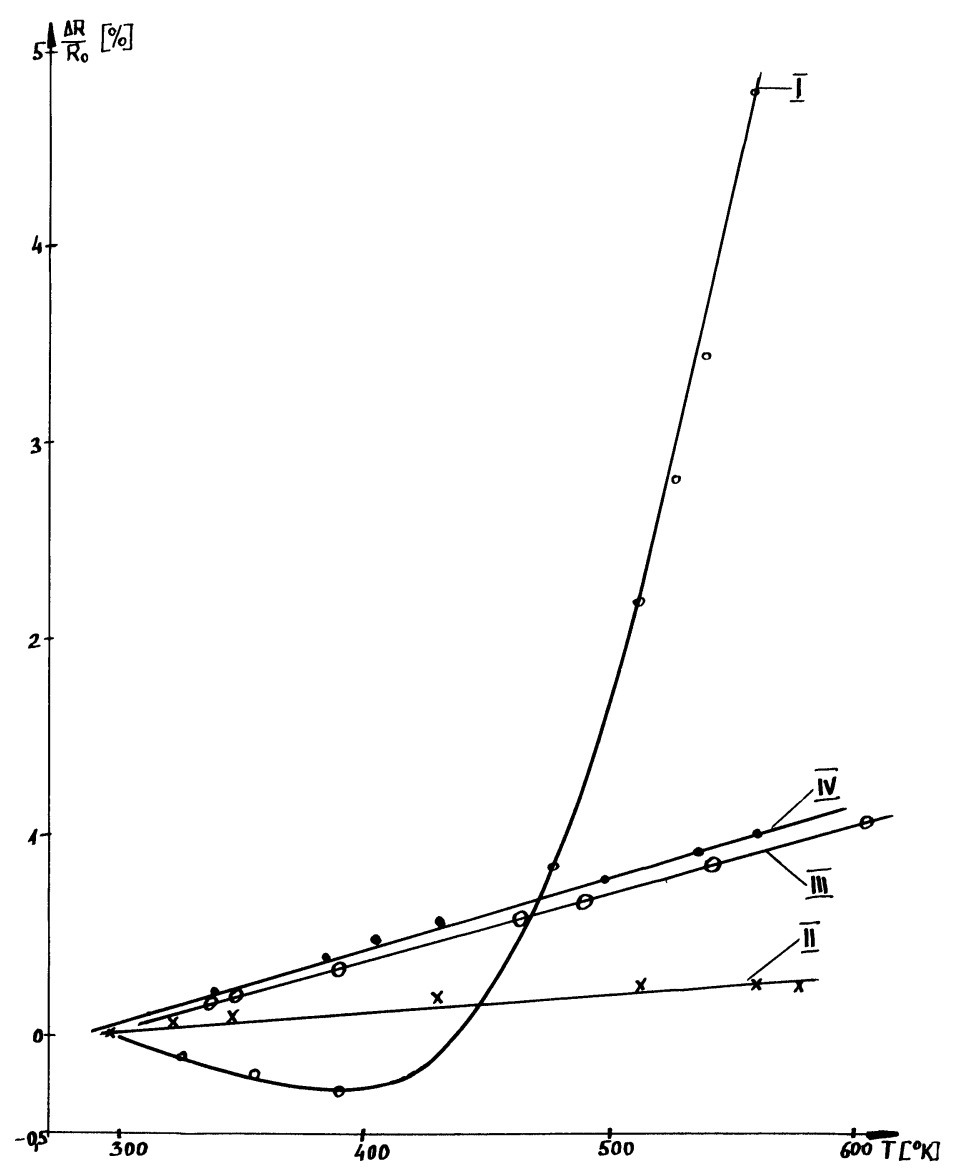

FIGURE 2 Temperature characteristics of resistance for resistor $19 \mathrm{~b} 5$ before each heat treatment (curves I-III) and after the last one (curve IV).

next heat treatment the temperature characteristic of resistance is again linear. However each subsequent heat treatment results in an increase of TCR.

The observed temperature characteristics of resistance can be explained as follows. Thin films of $\mathrm{NiCr}$ before heat treatment consist of small islands of metal surrounded by semi conducting grain boundaries. At a temperature below $400^{\circ} \mathrm{K}$ the grain boundaries contribute to the conduction of the thin films. The behaviour of the temperature characteristics of resistance after heat treatment seems to indicate that the semiconductor grain boundaries are disappearing during the heat treatment process. As a result of the subsequent heat treatment, the temperature characteristics of resistance remain linear over the full range of temperature, but the TCR, as well as the resistance, increases. At the end of the heat treatments the TCR of the sample $19 \mathrm{~b} 4$ was $+200 \mathrm{ppm} /{ }^{\circ} \mathrm{K}$ at a sheet resistance of $260 \Omega / \mathrm{sq}$.
The increase of resistance as a result of sequential heat treatment can be explained by the thinning of the film and the result of the oxidation of the film. The affinity of chromium to oxygen is larger than the affinity of nickel. It is thus very probable that only the chromium is oxidised. This is in agreement with the conclusion of Nocerino and Singer. ${ }^{3}$ As a result the concentration of non-bonded chromium in the interior of the films is decreased and the TCR increases because of the depletion of the metallic chromium content of the film.

\section{REFERENCES}

1. K. Hieber and L. Lassak. Thin Solid Films, 17, 105 (1973).

2. K. Hieber and L. Lassak. Thin Solid Films, 20, 63 (1974).

3. G. Nocerino and K.E. Singer, J. Vac. Sci. Technol. 16, 147 (1979). 

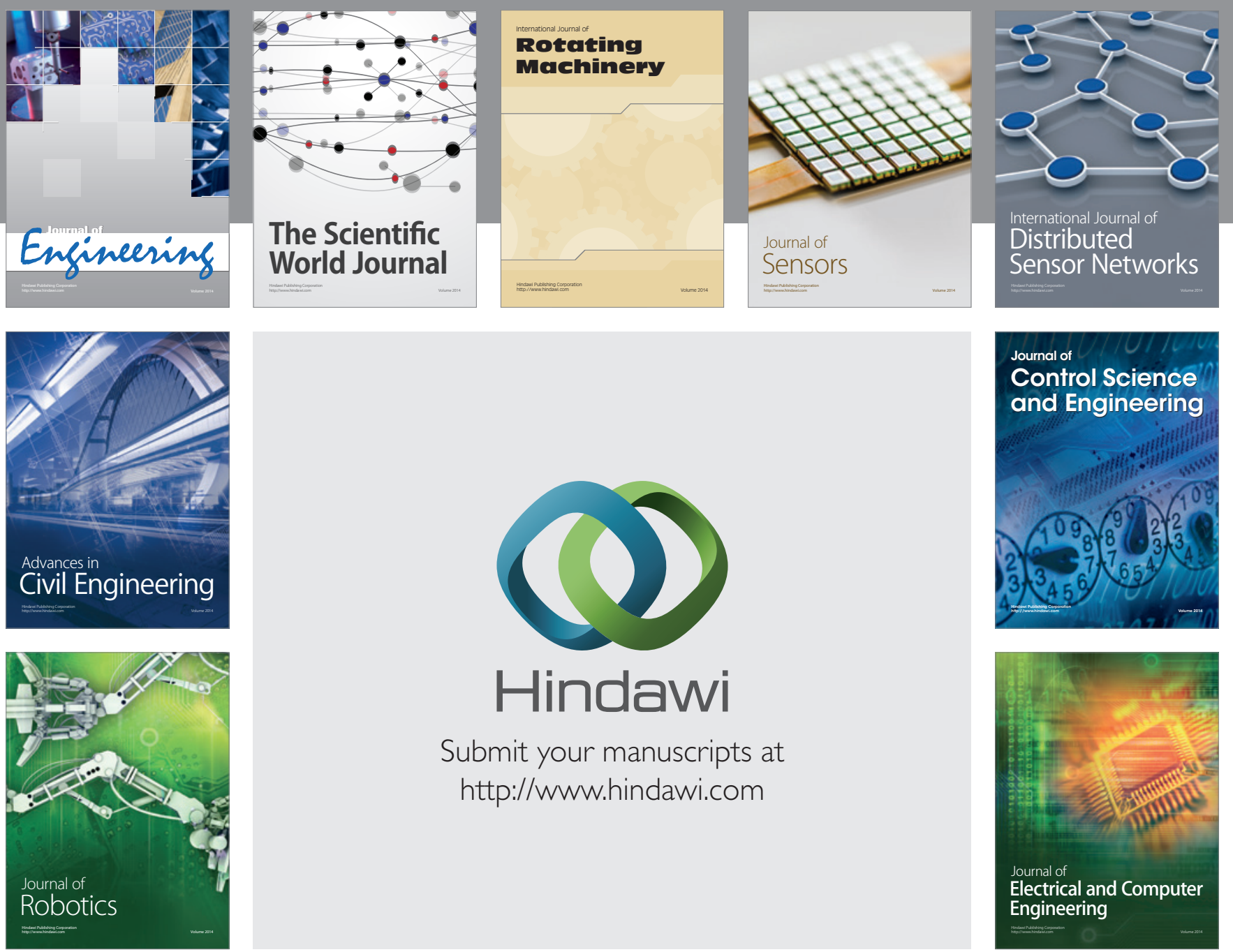

Submit your manuscripts at

http://www.hindawi.com
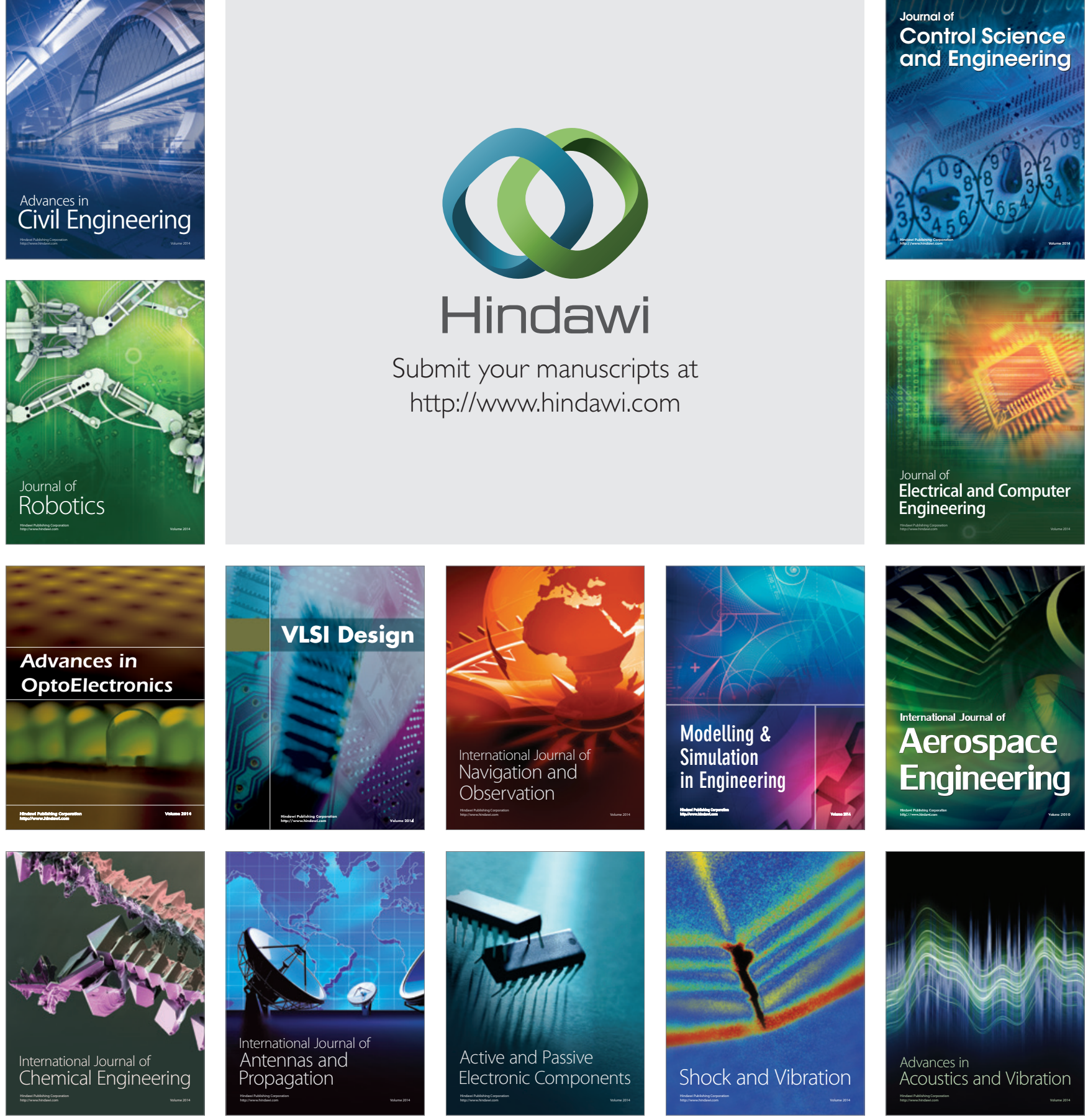